\title{
Serviço logístico de carga expressa no ramo bancário: uma experiência bem-sucedida
}

\begin{abstract}
RESUMO
O caso em estudo mostra a comparação entre dois modelos de serviços logísticos de um banco que decidiu terceirizar, em 2012, as atividades de apoio, serviço logístico expresso de entrega de cartões, malotes e documentos registrados, dentre outros, para um operador logístico. O método de pesquisa é quali-quantitativo, por intermédio de entrevista semiestruturada e observação participante na instituição pesquisada. Os resultados mostraram, por meio de indicadores de desempenho de processo, a situação do período anterior à terceirização em 2011; posteriormente, avaliou-se o processo terceirizado, em 2012, que não obteve o resultado esperado pelo banco e, por fim, analisou-se o período de 2013, considerando o novo operador logístico e, dessa vez, mostrou-se um caso de sucesso. Um aspecto relevante deste estudo é mostrar a importância de se implementar indicadores de desempenho para o controle do processo para a tomada de decisão no que tange a melhorias e alinhamento dos objetivos do negócio, além de considerar nas decisões de terceirização os ganhos financeiros, levar em conta o aspecto estratégico da operação.
\end{abstract}

Palavras-chave: Logística. Operador logístico. Indicadores de desempenho. Carga Expressa. 


\section{INTRODUÇÃO}

As empresas têm se comprometido em adicionar mais eficiência aos seus processos, para atender às demandas dos seus clientes, o que permite o aumento da produtividade, refletindo assim em uma vantagem competitiva para a empresa.

Para as companhias, trabalhar parâmetros qualitativos passa a ser importante para o acréscimo da satisfação dos seus clientes, fornecendo destaque aos mecanismos de mensuração e de monitoramento dos processos. Tais recursos podem ser traduzidos por meio de indicadores, que fornecem aos gestores toda a posição necessária a fim de que as ações sejam tomadas, medidas e monitoradas (RODRIGUES et al., 2011).

O transporte rodoviário desempenha um papel vital para a economia e para a nação, destacandose por possuir grande flexibilidade. Logo, acompanhar o desempenho das atividades de transporte, monitorando-as constantemente por meio de indicadores de desempenho, possibilita uma visão dos pontos em que a cadeia de suprimentos pode ser melhorada para obter vantagens competitivas, porque o transporte é o mais importante dos processos logísticos, tanto pela quantidade e valor dos recursos que consome, como por movimentar produtos de um ponto geográfico a outro (TABOADA, 2002).

Na prática, organizar o setor de transporte de uma empresa representa aumento de responsabilidades e de custos; sendo assim, as empresas preferem buscar agentes especializados como, por exemplo, um operador logístico (OPL). Isso ocorre principalmente no mercado de entregas rápidas, que cobre todo o território de um país com um nível de serviços uniforme, que possibilita para as empresas contratantes reduzir significativamente seus níveis de estoque, por meio da concentração dos produtos em poucos centros de distribuição e a mercadoria sendo deslocada desses pontos para os consumidores finais.

Porém, o relacionamento, que é geralmente conflitante entre os colaboradores internos da organização (TERAM, 2010), tem esses conflitos amplificados com a chegada de um OPL terceirizado. Portanto, os gestores das áreas de Materiais e Logística precisam ser habilidosos na decisão de contratar um OPL, porque os funcionários do referido segmento são vistos como prestadores de serviços subalternos. Assim, o contratante não se preocupa em integrá-los como parte estratégica do negócio, dessa maneira, aproximadamente $70 \%$ dos contratos encerram-se em conflito antes do prazo (FLEURY; WANKE; FIGUEIREDO, 2006).

Os insucessos acontecem pelo fato de as empresas não terem planejado corretamente a estratégia de operação, porque não estudaram os critérios e não utilizaram indicadores de desempenho (OLIVEIRA NETO, 2008).

O presente estudo propõe avaliar o desempenho logístico do serviço de transporte de carga expressa de um banco que optou por terceirizar as atividades de apoio, como o serviço logístico expresso de entrega de cartões, malotes e documentos registrados, dentre outros, para um OPL. Os resultados mostraram, por meio do indicador de desempenho de eficiência de processo, que o índice de eficiência regrediu logo após a implantação, ocasionando apreensão por parte do banco e na busca de negociação com o OPL. Este, entretanto, negou-se a atender às reivindicações e encerrou as negociações, o que culminou na decisão de rescisão contratual.

Assim, o banco decidiu procurar outro OPL no mercado e considerou a falta de transparência no que tange à avaliação dos índices de eficiência o principal problema e, fundamentado na experiência malsucedida, procurou a formalização contratual, utilizando os indicadores de desempenho como uma ferramenta de avaliação e acompanhamento das operações, para servir de base nas reuniões periódicas para melhorias, e a cobrança de multa em caso de ineficiência no processo.

Este artigo apresenta, além desta parte introdutória, o referencial teórico sobre carga expressa e indicadores de desempenho. Em seguida, é relatado o estudo de caso e são apresentados os procedimentos metodológicos, análise e discussão dos dados e, finalmente, são expostas as considerações finais e sugestões para pesquisas futuras. 


\section{TERCEIRIZAÇÃO DOS SERVIÇOS LOGÍSTICOS DE CARGA EXPRESSA}

Nesta seção, serão apresentados os itens sobre carga expressa, terceirização dos serviços logísticos e indicadores de desempenho.

\subsection{Carga expressa}

Desde os primórdios da logística, exigia-se que se obtivessem as formas mais econômicas, racionais e rápidas para se mobilizar armamentos, pessoas e provisões, utilizando-se do transporte. Porém, com o passar dos anos, a complexidade aumentou no que diz respeito à competitividade. Slack, Chambers e Johnston (2002) salientam que os objetivos de desempenho da indústria foram evoluindo ao longo dos anos, e o custo, a qualidade, o prazo de entrega e a flexibilidade tornaram-se elementos essenciais para o atendimento de clientes no tempo certo.

Segundo Vendrametto, Oliveira Neto e Santos (2008), a evolução dos procedimentos de produção, ao aumento do uso de sistemas de comunicação e controle, a liberação do comércio e a competição por mercados levaram a mudanças consideráveis na maneira de produzir e gerenciar os negócios.

A facilidade de acesso às novas tecnologias, o incremento das vendas pela Internet, a procura constante por menores custos, a repulsa aos riscos e a insegurança são alvos de preocupação e de análise no que concerne à resposta rápida aos clientes. A determinação das empresas de criar valor para os clientes obrigou a produção migrar de "empurrada pela empresa" para a "puxada pelo cliente", processo também denominado como just in time.

Esses fatores atuam de forma conjunta e têm criado a necessidade de se transportar quantidades e volumes cada vez maiores de pessoas e de mercadorias, de maneira expressa por todo o mundo e com custos cada vez menores, tornando-se um direcionador de mercado para o desenvolvimento desse negócio.

Carga expressa é uma operação porta a porta de entrega a partir do ponto de recolha até o ponto de entrega. Normalmente, é o tipo mais rápido possível de entrega e pode ser identificado em qualquer ponto da cadeia de suprimentos por meio de sistemas de identificação (BREWER; BUTTON; HENSHER, 2001).

A carga expressa consiste em toda e qualquer encomenda que tenha prioridade de prazo de entrega sobre as demais e que não dependa de consolidação para efeito de preço. O prazo de entrega de uma entrega doméstica pode variar de zero a três dias, dependendo da localidade, e é realizada de porta em porta por meio de transporte aéreo e rodoviário. Os tipos de volumes manuseados podem segmentar a carga expressa em envelopes (peso até $1 \mathrm{~kg}$ ), caixa pequena (peso até $2 \mathrm{~kg}$ ), caixa média (peso até $5 \mathrm{~kg}$ ) e volumes até $30 \mathrm{~kg}$ que possam ser normalmente manuseados por uma pessoa (FUERTH; DANTAS, 2007).

Para acompanhar o transporte de carga expressa, as organizações estão utilizando a Internet com a finalidade de se comunicar com seus consumidores e fornecedores, criando novas redes digitais de comércio eletrônico que evitam os canais de distribuição tradicionais. O principal objetivo é ter a resposta no momento desejado pelo cliente quanto ao status da entrega. Além disso, a usabilidade de tecnologia de Internet para melhorar a informação da carga expressa tem um custo elevado de implantação, mas reduz radicalmente os custos de transação e o prazo de entrega dos bens, especialmente aqueles que são puramente digitais (LAUDON; LAUDON, 2004).

Apesar de algumas empresas de grande porte terem a possibilidade de optar pelo sistema próprio de entregas para as compras realizadas por intermédio do comércio eletrônico, a maioria procura utilizar serviços logísticos de terceiros. Esses são normalmente representados por empresas de entrega rápida, couriers e transportadora de carga fracionada (FUERTH; DANTAS, 2007).

A partir da década de 1950, com a intensificação do processo de industrialização do Brasil, surgiu a necessidade de agilização e regularidade na troca de correspondências e encomendas entre as diversas unidades de uma mesma organização com atuação em âmbito nacional. Basicamente essas trocas de malotes davam-se entre matriz e filiais e vice-versa.

Os primeiros serviços de Transporte de Carga Expressa executados foram iniciados pelas principais empresas de aviação do Brasil, criadas na primeira metade do século XX com a Viação Aérea Rio-Grandense (VARIG), em 1927, e Viação Aérea São Paulo S/A (VASP), em 1933. Tais empresas transportavam cargas urgentes, como medicamentos, malas postais, peças para consertos de 
máquinas e jornais (LEITE FILHO, 2006).

Os Correios, em 1970, já sob a denominação atual Empresa Brasileira de Correios e Telégrafos (ECT), criaram o Serviço de Correspondência Agrupada (SERCA) e deram início ao transporte de carga expressa, essencialmente intercâmbio de malotes. Em 1982, foi criado o Serviço Especial de Encomenda Expressa (SEDEX), destinado a objetos de até $5 \mathrm{~kg}$, dispondo de coleta e entrega domiciliar no prazo máximo de 24 horas. No início, restrito a algumas capitais, o serviço sofreu grandes transformações, não apenas em decorrência da demanda, mas nas exigências do mercado em virtude da atuação da concorrência observada no segmento (LEITE FILHO, 2006).

O serviço SEDEX padrão hoje é prestado para mais de 4.000 municípios, possui limite de peso de $30 \mathrm{~kg}$ e prazos de entrega variados, em razão da localidade destino. Em 1989, foi criado o SEDEX VIP, que consistia na entrega, no mesmo dia, de cargas originadas das cidades do Rio de Janeiro, São Paulo e Brasília, e com destino a elas. Esse serviço passou a ser operado, com exclusividade, por aeronaves especialmente fretadas e identificadas com as cores e logomarca da ECT (LEITE FILHO, 2006).

No Brasil, o sistema de carga expressa como conhecido atualmente iniciou no fim da década de 1990. Basicamente havia duas empresas que trabalhavam dentro do conceito de carga expressa porta a porta, a ECT e a Vaspex, uma divisão do sistema de transporte rodoviário e aéreo de carga da VASP, que surgiu com um recorde na história do Franchising ${ }^{1}$ mundial, pois a rede foi inaugurada já contando com mais de cinquenta unidades franqueadas. Tal modelo de gestão, inclusive, já havia sido implementado com sucesso pela ECT, segundo Leite Filho (2006). A diferença básica entre as duas empresas era que a maioria do atendimento dos Correios era dada a pessoas físicas. Enquanto o sistema Vaspex atendia a ambos, com destaque às pessoas jurídicas pelo sistema just in time (BENZI, 1997).

Até 2004, a Vaspex foi líder do setor de encomendas expressas do mercado doméstico privado. Com a crise na VASP, a VarigLog, empresa de carga do grupo VARIG, conquistou aproximadamente metade do mercado da Vaspex (FINAMORE et al., 2007).

É importante ressaltar que esse serviço de transporte de carga expressa possui características operacionais e modalidades diversas com limites de prazo, peso e atendimentos diferenciados de localidades, conforme Leite Filho (2006). Logo, os clientes estão analisando os atributos, como regularidade nas entregas, segurança, agilidade e atendimento, quando se trata de carga expressa. Sendo assim, o preço deixou de ser a principal característica na decisão do contratante.

Neste estudo, o banco decidiu terceirizar o serviço de carga expressa de malotes para um OPL. A organização considerou essa atividade como apoio ao sistema logístico, no qual não compensa desenvolver estrutura logística para o atendimento de entregas rápidas.

\subsection{Terceirização de serviços logísticos}

Nesta seção, primeiramente será apresentada breve revisão sobre a evolução da logística no contexto organizacional e, em seguida, a perspectiva de terceirização das atividades de logística para um agente especializado.

No fim dos anos de 1960 e início dos de 1970, a logística havia se tornado independente e se colocado como uma área de responsabilidade e autoridade organizacional, geralmente com foco na distribuição física ou na gestão de materiais (BOWERSOX; CLOSS; COOPER, 2006). De 1970 em diante, as organizações atribuíam atenção para o gerenciamento da cadeia de suprimentos (NOVAES, 2007). Segundo Harrison e Hoek (2003), gerenciamento da cadeia de suprimentos estabeleceu-se no alinhamento das habilidades a montante e a jusante dos colaboradores da cadeia de suprimento para oferecer valor superior ao cliente final com o mínimo de custo para a cadeia de suprimento.

A questão logística evoluiu a partir de uma função de absorção de custo para uma função de estratégia que proporciona vantagem competitiva. Sendo assim, surgiu a necessidade na busca pela excelência no nível dos serviços de armazenagem, transporte e comunicação aos OPLs, o que tem alargado a capacidade destes em ofertar uma ampla gama de funções logísticas (GADDE; HULTHEN, 2009).

'Franchising é um método de arranjo para a distribuição de produtos e/ou serviços. Juridicamente, implementa-se por meio de um contrato pelo qual o detentor de um nome, marca, ideia, tecnologia, segredo, processo, proprietário ou fabricante de produto ou equipamento, mais know-how a ele relacionado denominado de franchisor ou franqueador, outorga a alguém jurídica e economicamente independente, denominado de franchisee ou franqueado, a licença para explorar essa operação (CHERTO, 1988), conduzir o negócio de certa maneira e por um período específico, conforme descrito no contrato de franquia (MORGENSTEIN; STRONGIN, 1992). 
Portanto, com o desenvolvimento dos processos de produção, as empresas verticalizadas convergiram-se na sua competência essencial, terceirizaram as atividades de apoio, enxugando as suas linhas, e estabeleceram verdadeiras parcerias com os fornecedores. Nesse cenário, as operações logísticas deixaram de ser assessórias e passaram a ser estratégicas (OLIVEIRA NETO, 2008).

$O$ conceito de terceirização ampliou-se à medida que as empresas tentaram adotar as técnicas do just in time e descobriram que as reorganizações internas na fábrica eram apenas parte do programa. Essas técnicas demandavam mudanças na cadeia de suprimentos, pois estão sujeitas aos relacionamentos compartilhados com os fornecedores, na busca pela vantagem competitiva para a organização (DORNIER et al., 2000).

Assim, surgiram os OPLs para atender às necessidades de mercado. Fleury e Ribeiro (2001a) ressaltam que a atividade de OPL no Brasil tornou-se mais notável a partir de 1994 com a estabilização econômica. A partir de 1997, grandes OPLs internacionais começaram a atuar no Brasil, ofertando novos serviços, que influíram para gerar novas necessidades nas empresas contratantes. Isso fez com que várias transportadoras se transformassem em OPLs para atender a essas novas necessidades de mercado (FLEURY; RIBEIRO, 2001b).

O OPL é o fornecedor de serviços especializados em gerenciar e executar as atividades logísticas nas diversas fases na cadeia de suprimento de seus clientes, e deve ter competência para, no mínimo, prestar serviços nas atividades básicas: controle de estoque, armazenagem e gestão de transporte. Os demais serviços ofertados funcionam como diferenciais de cada operador. Podem-se citar, como exemplo, análise e projeto de administração de estoques e de informação, gestão e rastreamento de pedidos, que podem estender-se até o gerenciamento da cadeia logística (FLEURY; WANKE; FIGUEIREDO, 2006).

A terceirização de serviços logísticos pode ser positiva para as organizações, pois contribui para o foco nas competências-chave, reduz custos, tempos de entregas e riscos, ajuda a acelerar processos de inovação e, consequentemente, consegue aumentar a satisfação do cliente e os lucros, conforme Graf e Mudambi (2005) e Narasimhan, Narayanan e Srinivasan (2010). Por outro lado, outras organizações podem perder com esses relacionamentos, já que os seus custos podem aumentar e a flexibilidade se reduzir, informações estratégicas tornarem-se públicas, e aumentar a dependência aos fornecedores pode-se tornar significativa, porque existe o risco de divulgação de conhecimento proprietário para fornecedores, que podem tornar-se seus concorrentes no futuro (HARRIS; GIUNIPERO; HULT, 1998).

Ainda que não haja consenso na literatura quanto ao efeito da terceirização no desempenho da empresa, a fim de obter mais-valia na terceirização, os OPLs devem ter uma boa compreensão do que é exigido por cada tipo de empresa e, assim, desenvolver estratégias para melhorar seus serviços a fim de agregar valor para os seus clientes (AKTAS et al., 2011).

Dessa forma, a decisão sobre o quê, quando e como terceirizar deve ser feita cuidadosamente, e os parceiros selecionados com critérios, porque os principais motivos para substituir um OPL levantados no Panorama de Terceirização Logística no Brasil (PTLB), pelo Instituto de Logística e Supply Chain (ILOS), em 2008, com 118 empresas são má qualidade dos serviços prestados (90\%), baixa capacidade de propor novas soluções logísticas (56\%), custos elevados (51\%), flexibilidade às mudanças (47\%), baixa disponibilidade de ativos por parte dos OPLs $(47 \%)$, pouca capacitação tecnológica $(44 \%)$, fragilidade financeira (37\%), problemas de segurança $(30 \%)$, dificuldade de relacionamento (29\%) e problemas éticos (27\%) (ILOS, 2009).

Por precaução, algumas empresas industriais tentam, por meio de contratos cada vez mais rígidos, constituir indicadores de eficiência a serem desempenhados pelos OPLs. De acordo com Barros (2009), outras ainda determinam prazos em contrato para que o OPL seja capaz de solucionar possíveis não conformidades e, ao término do prazo, como penalidade, o contrato pode ser revogado sem ônus para o contratante. Como em média o tempo de contrato no Brasil é de 2,1 anos, muitos OPLs resistem em investir em soluções inovadoras com retorno de investimento em longo prazo, 0 que reduz a capacidade de apresentar novas soluções logísticas.

Logo, os estudos comprovam a importância de avaliar a terceirização de serviços logísticos na estratégia da organização.

\subsection{Indicadores de desempenho}

Neste tópico, será mostrada a importância de constituir indicadores de desempenho logístico e 
sua utilização para o controle nos processos operacionais.

Indicadores de desempenho são empregados para melhorar os processos. De acordo com Forslund (2007), as etapas de gestão de desempenho são as seguintes: estabelecer objetivos e estratégias; definir métricas; estabelecer metas; medir; analisar; avaliar; e, em seguida, atuar para melhorar o processo.

Indicadores de desempenho em logística variam de medidas de alto nível de monitoramento dos processos logísticos até os níveis específicos das atividades, (GRIFFIS et al., 2007), porque são elementos-chave do sistema de controle, propiciando ações e decisões coerentes e orientadas para a estratégia (DORNIER et al., 2000), e possibilitam que as avaliações sejam feitas com base em fatos, dados e informações quantitativas, o que oferece maior confiabilidade nas decisões (CAIXETA-FILHO; MARTINS, 2001).

Os objetivos usuais de gestão de desempenho são para diminuir custos e melhorar a eficiência e eficácia. Uma questão que se coloca é se um item, um lote, uma unidade de carga de um veículo ou embarcação, um sistema de transporte completo ou até mesmo uma cadeia logística é o melhor nível de análise. Este é, naturalmente, sujeito a contexto, à categoria de indicador de desempenho utilizado e às suas metas individuais (WOXENIUS, 2012).

Depois de selecionar as medidas de desempenho adequadas ao sistema logístico, é preciso implementar e controlar o esforço logístico por meio dos indicadores de desempenho, segundo Ballou (1993). Esse processo pode ser descrito por três itens: (1) padrões ou meta, (2) medidas e (3) comparação e ação corretiva (Figura 1).

Figura 1 - Modelo para controle logístico

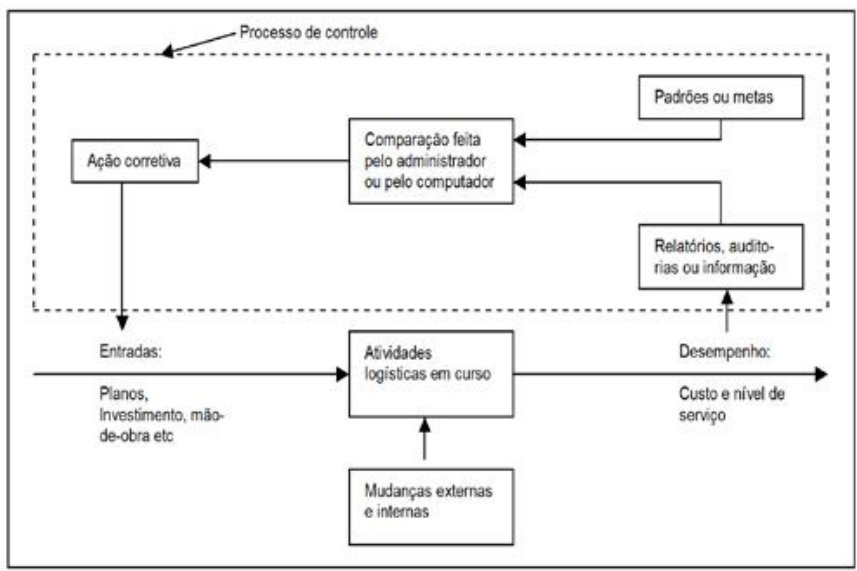

Fonte: Ballou (1993, p. 38)

Segundo Moreira (2009), o indicador mais apropriado para a avaliação no que tange à carga expressa é o indicador de eficiência, porque demonstra que os pedidos foram expedidos no prazo, não há nenhum item estocado na expedição, está havendo uso adequado de equipamentos durante a expedição, bom uso da área de expedição, pedidos conduzidos pontualmente e avaliação periódica do nível de serviço ao cliente.

Portanto, a capacidade realizada, quando comparada à capacidade efetiva, fornece a porcentagem de eficiência da unidade produtora em realizar o trabalho programado (MOREIRA, 2009).

\section{ESTUDO DE CASO}

A organização do ramo bancário decidiu terceirizar, em 2012, o serviço de carga expressa de malotes para um OPL. O banco considerou essa atividade como apoio ao sistema logístico, já que não compensava desenvolver estrutura logística própria para atendimento de entregas rápidas.

O processo logístico, para o atendimento do setor bancário, visa à entrega expressa de envelopes (peso até $1 \mathrm{~kg}$ ), caixa pequena (peso até $2 \mathrm{~kg}$ ), caixa média (peso até $5 \mathrm{~kg}$ ) e volumes até $30 \mathrm{~kg}$. $\mathrm{O}$ entrevistado relatou que o banco considerou que não compensava investir na estrutura logística para essa atividade, que seria: investimento em motos e furgões e contratação de pessoal para a atividade operacional e administrativa. Outro aspecto relatado foi quanto à responsabilidade pela gestão das entregas porque, além de ser o foco essencial do negócio bancário, caso não seja gerida com eficiência, poderia afetar a imagem do banco no mercado. 
Sendo assim, a organização estabeleceu o processo logístico em negociação com o OPL, na qual o banco desenvolveu o setor de serviços de malotes, local para a expedição de documentos, onde se solicita o serviço de coleta expresso, que é operado pelos funcionários da OPL.

Em seguida, os motociclistas ou motoristas dos furgões retiram no setor de serviços os malotes, os envelopes, caixas pequenas e médias com peso até $30 \mathrm{~kg}$ e levam até o galpão de carga expressa do OPL.

Essa estrutura do OPL foi desenvolvida para o atendimento mais responsivo. A seguir são descritas as operações no armazém de carga expressa:

a) No galpão de carga expressa, a primeira etapa consiste na preparação da remessa; é feito o cadastro do objeto com a finalidade de gerar identificação e rastreabilidade do produto e, para isso, utiliza-se o sistema de código de barra.

b) A segunda etapa visa à separação dos malotes com o foco no destino para a entrega nacional e/ou internacional. Consiste em um estudo para mensurar o volume por destino.

c) Na terceira etapa, com o plano do destino traçado, gera-se a lista de expedição em que o OPL separa fisicamente os objetos por destinatário e realiza a operação de unitização da carga em lotes, com o objetivo de aproveitar o máximo possível a capacidade de carga do veículo que fará a entrega.

d) Na quarta etapa, os objetos são transportados. Em locais mais próximos, são utilizados motociclistas, com o envio de correspondência registrada diretamente aos clientes, e, em regiões distantes, furgões. Nas regiões afastadas, incluem-se os serviços de entrega e retirada no aeroporto, que consiste nos objetos com destino fora do raio de atuação local, geralmente para outros estados. Outro aspecto a ser salientado é que o OPL tem sua estrutura expressa montada nos principais estados do Brasil. Assim sendo, quando os objetos chegam ao estado de destino, o OPL retira os objetos e repetem-se as mesmas rotinas pelo galpão de carga expressa local.

Na Figura 2, é possível visualizar o processo logístico expresso utilizado pelo setor bancário para a entrega de malotes.

Figura 2 - Processo de logística expressa para entrega de malotes

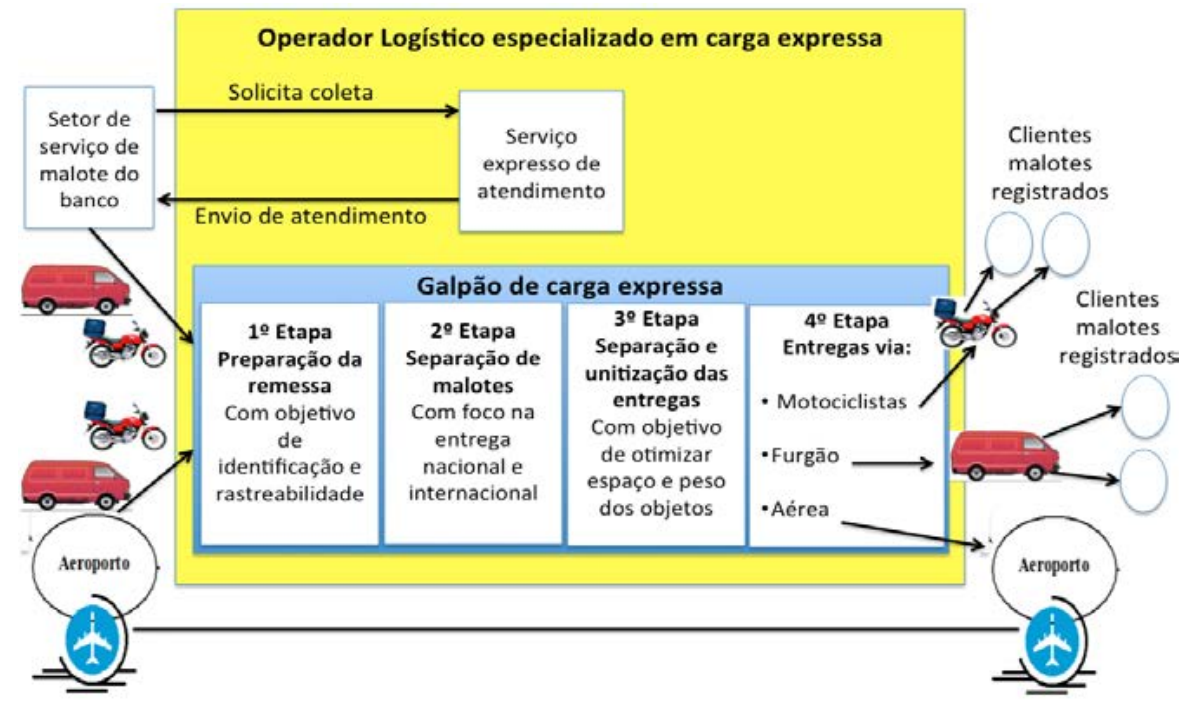

Fonte: Elaboradores pelos autores, adaptado dos documentos da empresa (2014)

É importante mencionar que o banco, após a terceirização do transporte expresso, continuou mensurando o desempenho do OPL, pois, segundo o entrevistado, "era preciso para verificar ao longo do tempo a eficiência do processo e intervir em caso de ineficiência"."

Além disso, o serviço logístico expresso é de suma importância para a vantagem competitiva nesse setor. O que justificou essa ação, de acordo com o entrevistado, é a satisfação do cliente, "que em se tratando de cartões de créditos, malotes, documentos registrados, dentre outros, no mínimo a entrega deve ser expressa, por dois motivos, segurança e confiabilidade na entrega". E o entrevistado continuou "quanto mais tempo o produto fica circulando antes da entrega, o risco de extravio é maior" e, em se tratando de documentações registradas, fica evidente a importância da responsividade com segurança e confiabilidade.

Dessa forma, foi calculada, pelo banco, a capacidade efetiva com os tempos em minutos das perdas planejadas, que são aquelas perdas que se sabe previamente que acontecerão, tais como: frequência de envio de cargas, pesagens, atendimento aos clientes, modalidade de captação, troca de turno de coleta, atendimento de coleta, frequência dos recebimentos, pesagens de cargas recebidas, modalidades de entrega, troca de turno de recebimento, entrega expressa, rastreabilidade e irregularidades, conforme relatado pelo entrevistado. 
No cálculo da capacidade realizada, também foram levados em consideração os tempos em minutos com as perdas não planejadas, que são perdas que não se consegue antever, tais como falta de pessoal em captação e distribuição, manutenção com quebra de equipamento e acidente de trabalho.

\section{PROCEDIMENTOS METODOLÓGICOS}

Os procedimentos metodológicos do presente estudo são de categoria exploratória e descritiva, de natureza qualitativa e quantitativa, método do estudo de caso, observação participante e entrevista semiestruturada. A categoria da pesquisa exploratória desenvolve: (a) levantamento bibliográfico; (b) entrevistas com pessoas que tiveram experiências práticas com o problema pesquisado; e (c) análise de exemplos que estimulem a compreensão (GIL, 2002).

A utilização do método de estudo de caso justifica-se pelo fato de atender às condições estabelecidas para testar os objetivos propostos no trabalho (YIN, 2003). Segundo Eisenhardt (1989), o estudo de caso é uma estratégia de pesquisa para entender a dinâmica presente em cada cenário. Estudos de caso geralmente agrupam métodos de coleta de dados, como arquivos, entrevistas, observações e questionários, e as evidências podem ser de natureza qualitativas ou quantitativas, ou ambas. Yin (2003) afirma que, dessa maneira, é possível criar as condições apropriadas para o entendimento, a refutação ou a confirmação da teoria, sendo um componente-chave para estudos exploratórios.

A observação participante e a entrevista semiestruturada são os instrumentos mais corriqueiros da pesquisa qualitativa e que melhor apresentam suas características (BOGDAN; BIKLEN, 1992). Geralmente, quando a pesquisa inicia-se pela observação participante, torna-se uma poderosa técnica da metodologia qualitativa, conforme McCracken (1991).

A entrevista com o representante do banco responsável pela terceirização da operação de carga expressa, por sua vez, propiciou acesso ao contexto do comportamento das pessoas e, desse modo, forneceu um modo de compreender o significado desses comportamentos (SEIDMAN, 1991). Além disso, obtiveram-se os dados quantitativos utilizado nesta pesquisa.

Por intermédio da análise qualitativa, foi viável examinar dados quantitativos a fim de facilitar o entendimento do objeto estudado. A pesquisa quantitativa permite a mensuração de atitudes, hábitos, opiniões e reações em um universo, por meio de uma amostra que o represente estatisticamente (DENZIN; LINCOLN, 2005; HAYATI; KARAMI; SLEE, 2006).

\section{ANÁLISE E DISCUSSÃO DOS DADOS}

A análise dos dados do objeto em estudo tem como foco a movimentação na captação e distribuição no transporte de carga expressa mensurado por meio do indicador de eficiência do processo, em 2011, 2012 e 2013. A análise foi realizada considerando as ocorrências das não conformidades na captação e distribuição de cargas expressas em minutos durante os períodos mencionados.

Relativamente à captação de carga expressa, foram levados em consideração os tempos gastos no atendimento de coleta, frequência de envio, informações para o atendimento aos clientes, modalidade de captação, pesagem, troca de turno de coleta e falta de pessoal.

Para a distribuição de carga expressa, consideraram-se os tempos gastos com frequência dos recebimentos, modalidade de entrega, pesagens, troca de turno de distribuição, rastreabilidade, eventuais irregularidades, falta de pessoal, quebra de equipamentos e acidente de trabalho.

A análise quantitativa desta pesquisa levou em consideração que, no período de 2011, a própria empresa era responsável pela captação e distribuição das cargas expressas na contratação de fretes.

No período de 2012, o banco optou pela contratação do OPL para a entrega expressa de cartões de crédito, malotes, documentos registrados, dentre outros; segundo o entrevistado, essas atividades são consideradas como atividade de apoio e o banco não tinha como administrar esses serviços. Também foi ressaltado pelo entrevistado que outro motivo para a terceirização é que poderia prejudicar a competência essencial do negócio.

Porém, ocorreu ineficiência no processo e o banco teve de encerrar o contrato e procurar no mercado outro OPL para o início das atividades em janeiro de 2013.

A Tabela 1 mostra as ocorrências em captação e distribuição de cargas expressas com seus respectivos tempos em minutos, representando as perdas planejadas, bem como as ocorrências das perdas não planejadas, que estão ressaltadas em vermelho (falta de pessoal, quebra de equipamento e acidente de trabalho), também em minutos, de janeiro a dezembro de 2011, 2012 e 2013.

Na parte inferior da Tabela 1, são apresentados os índices de eficiência de serviços, a capacidade efetiva e a capacidade realizada representados em horas. Para o cálculo da capacidade efetiva, foi 
utilizada a somatória dos valores correspondentes às perdas planejadas em minutos, dividindo-os por 60 para obterem-se os valores em horas; em seguida, multiplicou-se por 30 que equivale ao número de dias de trabalho por mês, exceto o mês de fevereiro, que foi considerado com 28 dias; em seguida, subtraiu-se o valor encontrado por 240, que representou a quantidade de horas trabalhadas durante o mês, exceto o mês de fevereiro, cujo valor de horas trabalhadas representou 224 horas.

Para o cálculo da capacidade realizada, foi utilizada a somatória dos valores correspondentes às perdas não planejadas em minutos, dividindo-os por 60 para obterem-se os valores em horas; em seguida, subtraiu-se do valor encontrado da capacidade efetiva e, assim, obteve-se a capacidade que realmente aconteceu em determinado período.

O cálculo do Índice de eficiência foi obtido pela divisão entre a capacidade realizada e a capacidade efetiva, multiplicado por 100, obtendo-se, assim, um valor percentual, conforme a fórmula a seguir.

$$
\text { Índice de eficiência }=\frac{\text { Capacidade realizada }}{\text { Capacidade efetiva }} \times 100
$$

Tabela 1 - Captação e distribuição de cargas expressas e índice de eficiência no período de 2011,

\begin{tabular}{|c|c|c|c|c|c|c|c|c|c|c|c|c|c|c|c|c|c|c|c|c|c|c|c|c|c|c|c|c|c|c|c|}
\hline \multirow{2}{*}{$\begin{array}{c}\text { Ocorrências em captação de cargas } \\
\text { expressas } \\
\text { (minutos) }\end{array}$} & \multicolumn{11}{|c|}{2011} & \multicolumn{10}{|c|}{2012} & \multicolumn{10}{|c|}{2013} \\
\hline & Jan & Fev & Mar & Abr & Mai & Jun $\mathrm{J}$ & Jul $A$ & $\begin{array}{lll}g_{0} \quad S \\
\end{array}$ & Set $\mathrm{Ou}_{\mathrm{u}}$ & ut Nov & Dez & $\operatorname{Jan} F$ & Fev Ma & Uar $\mathrm{Abr}$ & Mai & Jun $\mathrm{J}$ & Jul $\mathrm{A}$ & Ago $\quad \mathrm{Se}$ & Set Out & Nov & Dez & Jan & Fev Ma & aar $\mathrm{Abr}$ & br Mai & & Jul $\mathrm{Ag}_{\mathrm{g}}$ & go Set & Out & Nov & $\overline{\text { Dez }}$ \\
\hline Frequência de envio de cargas & 3 & 4 & 3 & 3 & 4 & 3 & 3 & 2 & 3 & 2 & 4 & 4 & 4 & 5 & 6 & 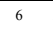 & - & 4 & $\begin{array}{cc}5 & 6 \\
5\end{array}$ & 5 & 6 & 5 & $\begin{array}{ll}4 & 4\end{array}$ & 4 & 45 & 5 & 3 & 2 & 3 & 2 & 3 \\
\hline agens das cargas & 1 & 1 & 2 & 1 & 1 & 2 & 2 & 3 & 1 & 2 & 3 & 2 & & 4 & 4 & 5 & 5 & 6 & & 6 & 7 & 6 & 5 & & 2 & & & & 2 & & \\
\hline dimento aos cli & 4 & 3 & 3 & 4 & 3 & 4 & 3 & 4 & 4 & 4 & 4 & 4 & 4 & 5 & 5 & 4 & 4 & 6 & 6 & 6 & 7 & 7 & 6 & & 3 & & & & 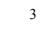 & 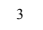 & 3 \\
\hline lalida & 20 & 22 & 20 & 24 & 23 & 22 & 19 & 192 & $24 \quad 20$ & $20 \quad 23$ & 23 & $24 \quad 2$ & $26 \quad 23$ & $23 \quad 28$ & 28 & 30 & $30 \quad 3$ & $30 \quad 32$ & $32 \quad 31$ & 32 & 34 & 32 & $\begin{array}{ll}31 & 31\end{array}$ & $\begin{array}{ll}31 & 28\end{array}$ & $8 \quad 25$ & 26 & 21 & $25 \quad 30$ & 18 & 20 & 21 \\
\hline no de & 30 & 32 & 35 & 31 & 35 & 32 & 34 & $27 \quad 3$ & $\begin{array}{ll}33 & 3 \\
3\end{array}$ & $35 \quad 31$ & 35 & $35 \quad 3$ & $\begin{array}{ll}37 & 36\end{array}$ & $\begin{array}{ll}36 & 39 \\
\end{array}$ & 39 & 38 & 393 & $\begin{array}{ll}38 & 40 \\
\end{array}$ & $\begin{array}{ll}40 & 39\end{array}$ & 41 & 43 & 41 & $\begin{array}{ll}41 \quad 28 \\
\end{array}$ & $28 \quad 30$ & $\begin{array}{lll}0 & 31\end{array}$ & 30 & 34 & 36 & 30 & 30 & 30 \\
\hline 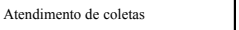 & 8 & 7 & 6 & 7 & 8 & 6 & 7 & 列 & 7 & 6 & 7 & 8 & 9 & 9 & 10 & 10 & 11 & $12 \quad 12$ & $12 \quad 12$ & 12 & 15 & 10 & 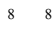 & 8 & 6 & 6 & 5 & & & & 4 \\
\hline Falta de pessoal & 160 & 150 & 160 & 150 & 130 & 160 & $\begin{array}{lll}150 \quad 1 \\
\end{array}$ & $140 \quad 16$ & $\begin{array}{ll}160 \quad 15 \\
\end{array}$ & $\begin{array}{ll}50 \quad 130 \\
\end{array}$ & 120 & $150 \quad 16$ & $160 \quad 160$ & $\begin{array}{ll}160 & 170 \\
\end{array}$ & 170 & $175 \quad 1$ & & $173 \quad 18$ & $\begin{array}{ll}80 & 180 \\
\end{array}$ & $\begin{array}{ll}0 \quad 185 \\
\end{array}$ & 190 & $170 \quad 1$ & $\begin{array}{ll}70 & 17 \\
\end{array}$ & $\begin{array}{ll}170 & 168 \\
\end{array}$ & $\begin{array}{ll}68 \quad 140 \\
\end{array}$ & & & 155 & 50 & 0 & 10 \\
\hline $\begin{array}{r}\text { Ocorréncias em dis } \\
\text { cargas expr }\end{array}$ & \multicolumn{11}{|c|}{2011} & \multicolumn{10}{|c|}{2012} & \multicolumn{10}{|c|}{2013} \\
\hline minuos) & \begin{tabular}{|l|} 
Jan \\
\end{tabular} & Fev & Mar & Abr & Mai & Jun & Jul $A$ & $\begin{array}{ll}g_{0} \quad S \\
\end{array}$ & Set $O_{1}$ & ut Nov & Dez & $\operatorname{Jan} F$ & Fev Mar & tar $\mathrm{Abr}$ & Mai & Jun J & Jul $\mathrm{A}$ & $\begin{array}{ll}\mathrm{Agg} \quad \mathrm{Se} \\
\mathrm{g}\end{array}$ & Set Out & Nov & $\begin{array}{l}\text { Dez } \\
\end{array}$ & Jan $\mathbf{F}$ & Fev $\mathrm{Ma}$ & har $\mathrm{Abr}$ & br Mai & Jun $J$ & Jul $\mathrm{Ag}$ & $\begin{array}{lll}\text { go } & \text { Set } \\
\end{array}$ & Out & Nov & Dez \\
\hline r & 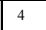 & 3 & 3 & 4 & 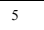 & 3 & 4 & 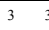 & 3 & 5 & - & 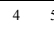 & 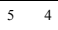 & - & 6 & - & & & & & 10 & & S & 7 & 4 & & & & - & & 4 \\
\hline agens $\mathrm{d}$ & 2 & 3 & 4 & 3 & 3 & 4 & 4 & 2 & 2 & 3 & 4 & 4 & 4 & 5 & 5 & 5 & & 1 & 6 & 8 & 12 & 10 & 6 & 6 & 4 & 3 & & & 3 & & 2 \\
\hline dalida & 30 & 32 & 28 & 29 & 27 & 28 & 30 & $34 \quad 2$ & 293 & $\begin{array}{ll}32 & 28\end{array}$ & 27 & 34 & $\begin{array}{ll}37 & 38\end{array}$ & $38 \quad 39$ & 40 & 39 & 39 & 42 & 41 & 241 & 43 & 41 & $\begin{array}{lll}37 & 35\end{array}$ & 35 & 30 & 25 & 20 & $25 \quad 30$ & 35 & 25 & 25 \\
\hline ca de & 40 & 38 & 35 & 42 & 40 & 40 & 45 & 38 & $\begin{array}{ll}38 & 4 \\
\end{array}$ & $40 \quad 35$ & 33 & $43 \quad 4$ & $\begin{array}{ll}48 & 50\end{array}$ & $50 \quad 51$ & 48 & 50 & 52 & $51 \quad 54$ & $54 \quad 53$ & $3 \quad 55$ & 54 & 51 & $\begin{array}{ll}46 & 47 \\
\end{array}$ & $\begin{array}{ll}47 \quad 43 \\
\end{array}$ & $\begin{array}{ll}3 & 38\end{array}$ & 31 & 35 & 31 & 30 & 30 & 31 \\
\hline Entrega expressa & 120 & 110 & 100 & 110 & 130 & 120 & 1201 & $100 \quad 13$ & $\begin{array}{ll}130 & 11 \\
3\end{array}$ & $10 \quad 100$ & 110 & $120 \quad 13$ & $125 \quad 126$ & $126 \quad 128$ & 126 & 1301 & 1311 & $127 \quad 13$ & $\begin{array}{ll}130 \\
132\end{array}$ & $\begin{array}{l}2 \quad 131 \\
\end{array}$ & 134 & 128 & $129 \quad 12$ & $\begin{array}{ll}125 & 120\end{array}$ & $20 \quad 110$ & 90 & 100 & $\begin{array}{ll}90 & 100\end{array}$ & $\begin{array}{ll}00 & 100\end{array}$ & 90 & 90 \\
\hline tre & 5 & 4 & 6 & 5 & 4 & 6 & 5 & 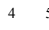 & 5 & 6 & 5 & 5 & 6 & 6 & 8 & 8 & 8 & $\begin{array}{ll}9 & 8\end{array}$ & $\begin{array}{ll}8 & 8\end{array}$ & 9 & 12 & 12 & $\begin{array}{ll}11 & 10\end{array}$ & 10 & 6 & 6 & ( & & 4 & 3 & 4 \\
\hline gu & 20 & 22 & 25 & 27 & 20 & 25 & 20 & 25 & 27 & 25 & 28 & 25 & $28 \quad 28$ & $\begin{array}{ll}28 & 27\end{array}$ & 29 & 28 & 30 & $\begin{array}{ll}29 & 27\end{array}$ & 27 & $\begin{array}{l}0 \\
0\end{array}$ & 31 & 33 & 30 & 28 & 29 & 25 & 20 & 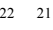 & 21 & 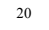 & 21 \\
\hline falta de $p$ & 18 & 180 & 170 & 160 & 180 & 180 & $\begin{array}{ll}170 \quad 1 \\
\end{array}$ & $\begin{array}{lll}160 & 18\end{array}$ & $\begin{array}{ll}180 & 17\end{array}$ & $\begin{array}{ll}70 & 180\end{array}$ & 170 & 180 & $\begin{array}{ll}180 & 170\end{array}$ & $\begin{array}{ll}170 & 160\end{array}$ & 180 & 1851 & 1901 & $\begin{array}{ll}165 & 17\end{array}$ & $\begin{array}{ll}170 & 185\end{array}$ & $\begin{array}{ll}5 & 190\end{array}$ & 180 & 175 & $\begin{array}{lll}170 & 17\end{array}$ & $\begin{array}{ll}170 & 155\end{array}$ & $\begin{array}{ll}55 & 150\end{array}$ & $\begin{array}{ll}150 & 1\end{array}$ & $\begin{array}{ll}160 & 1\end{array}$ & $\begin{array}{ll}170 & 160\end{array}$ & $\begin{array}{lll}50 & 150\end{array}$ & 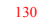 & 120 \\
\hline $\mathrm{b}$ & 25 & 240 & 250 & 230 & 240 & $250 \quad 2$ & 2402 & $\begin{array}{ll}250 & 23\end{array}$ & $230 \quad 25$ & $250 \quad 230$ & 220 & 250 & $\begin{array}{lll}270 & 260\end{array}$ & 600 & 270 & $240 \quad 2$ & $270 \quad 2$ & $\begin{array}{lll}265 & 28\end{array}$ & $280 \quad 275$ & $\begin{array}{lll}5 & 265\end{array}$ & 260 & 260 & $240 \quad 22$ & $220 \quad 210$ & $\begin{array}{ll}10 & 190\end{array}$ & 180 & 2 & $\begin{array}{lll}200 & 210\end{array}$ & $\begin{array}{ll}10 & 200\end{array}$ & 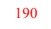 & 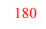 \\
\hline cidider & & 130 & 140 & 130 & 140 & & & 100 & 140 & $120 \quad 140$ & 130 & 15 & & & 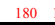 & & & 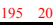 & 200 & & & & & & & & & & & & \\
\hline İndice & \multicolumn{11}{|c|}{2011} & \multicolumn{10}{|c|}{2012} & \multicolumn{10}{|c|}{2013} \\
\hline расас. Realzada / С арас. & \begin{tabular}{|l|} 
Jan \\
\end{tabular} & $\mathrm{Fev}$ & Mar & Abr & $\begin{array}{l}\text { Mai } \\
\end{array}$ & $\begin{array}{l}\text { Jun } \\
\end{array}$ & Jul $A$ & $\begin{array}{lll}g_{0} \quad S & \end{array}$ & et 0 & uut Nov & Dez & Jan $F$ & $\mathrm{Fev}$ Mar & tar Abr & Mai & Jun J J & $\begin{array}{ll}\text { Jul } A \\
\end{array}$ & $\begin{array}{lll}\mathrm{Agg} & \mathrm{Se} \\
\mathrm{g}\end{array}$ & Set Out & if Nov & $\begin{array}{l}\text { Dez } \\
\end{array}$ & $\begin{array}{l}\text { Jan } \\
\end{array}$ & Fev Ma & ar $\mathrm{Abr}$ & br Mai & $\begin{array}{l}\text { Jun } \\
\end{array}$ & Jul $\mathrm{A}$ & $\begin{array}{lll}\mathrm{gog} & \text { Set } \\
\end{array}$ & et Out & Nov & Dez \\
\hline acida & 96 & 93 & 105 & 96 & 89 & 93 & $\begin{array}{ll}92 & 1\end{array}$ & 106 & 87 & 106 & 96 & 84 & $\begin{array}{ll}67 & 71\end{array}$ & 71 & 63 & 61 & J1 & 5 & 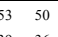 & 47 & 36 & 48 & 54 & 72 & 97 & 113 & & $12 \quad 106$ & & 123 & \\
\hline . & 84 & 81 & 93 & 85 & 77 & 81 & 81 & 95 & 75 & 95 & $x^{2}>$ & 72 & 54 & 58 & 50 & 47 & 43 & 39 & 39 & 33 & 22 & 34 & 41 & & 85 & & & & 5 & & \\
\hline
\end{tabular}

Fonte: Dados da pesquisa (2014)

A Tabela 2 mostra o comparativo da variação percentual realizado entre os períodos de 2011, quando a operação era realizada pelo próprio banco, e 2012, quando a operação passou para OPL; os valores da variação percentuais foram negativos de um período em relação ao outro. É importante salientar sobre a necessidade da mensuração do desempenho por meio do indicador de eficiência no processo para a tomada de decisão. Em primeira instância, a decisão foi de exigir melhorias do OPL, porque, antes da terceirização, o banco gerenciava a captação e entrega da carga expressa e os resultados eram melhores.

Tabela 2 - Comparativo e variação percentual dos Índices de eficiência entre 2011 e 2012

\begin{tabular}{|c|c|c|c|c|c|c|c|c|c|c|c|c|}
\hline Eficiência 2012 / 2011 & Jan & Fev & Mar & Abr & Mai & Jun & Jul & Ago & Set & Out & Nov & Dez \\
\hline Índice de Eficiência 2011 & $88 \%$ & $87 \%$ & $89 \%$ & $88 \%$ & $87 \%$ & $87 \%$ & $88 \%$ & $90 \%$ & $86 \%$ & $88 \%$ & $89 \%$ & $89 \%$ \\
\hline Índice de Eficiência 2012 & $85 \%$ & $81 \%$ & $82 \%$ & $80 \%$ & $79 \%$ & $78 \%$ & $76 \%$ & $76 \%$ & $74 \%$ & $72 \%$ & $71 \%$ & $61 \%$ \\
\hline Variação $\Delta \%$ & $-2 \%$ & $-8 \%$ & $-7 \%$ & $-9 \%$ & $-9 \%$ & $-10 \%$ & $-14 \%$ & $-15 \%$ & $-14 \%$ & $-18 \%$ & $-21 \%$ & $-31 \%$ \\
\hline
\end{tabular}

Fonte: Dados da pesquisa (2014)

Segundo o entrevistado, havia a expectativa de que a terceirização fosse melhorar os índices de eficiência negociada a 95\%. Porém, os dados mostraram ineficiência; além disso, o OPL recusou-se a efetuar novas negociações, e a decisão de cessação do contrato com o OPL não foi possível ser evitada, porque o OPL não tinha como aumentar a sua infraestrutura de operação, corroborando com os achados de Harris, Giunipero e Hult (1998), em relação à dificuldade do OPL em ajustar a sua infraestrutura para atender à necessidade do contratante.

Dessa forma, o banco não tinha como operar o processo logístico de carga expressa, de acordo com o entrevistado, porque perderia o foco do negócio e decidiu buscar novamente a opção de contração do OPL no mercado. Na análise de mercado que visou selecionar um novo OPL que atendesse às suas necessidades, defrontou-se com uma grande dificuldade em encontrar um OPL 
que aceitasse as exigências contratuais para a operação bancária.

Ainda, conforme o entrevistado, os negociadores de serviços dos OPLs preferem vender pacotes de serviços para organizações que não fizeram um prévio estudo no que tange a critérios contratuais específicos, indicadores de desempenho e cobrança de multas em caso de ineficiência.

Nessa nova negociação com outro OPL para o ano de 2013, o banco decidiu ser mais transparente no que se refere à importância da eficiência do processo e acrescentou a mensuração do desempenho no contrato associado a multas em caso de ineficiência; porque não importa se o banco adota as melhores práticas, se seus fornecedores forem onerosos e/ou o OPL for ineficiente no atendimento às expectativas dos clientes, conforme Di Serio e Sampaio (2001).

Conforme o entrevistado, essa transparência em relação à mensuração do desempenho e multa em caso de ineficiência foi necessária, dado que, na negociação anterior, "essa ação falhou, não adianta contratar um OPL sem considerar o mesmo agente integrador do negócio da empresa, é preciso transparência sobre os aspectos de mensuração de desempenho e cobrar multas pela falta de atendimento a essas necessidades negociadas e formalizadas em contrato".

O banco, na formalização contratual, estabeleceu que, depois de seis meses, contados a partir de janeiro de 2013, a eficiência do processo mensal deveria mostrar índice de $90 \%$ de nível de atendimento.

As multas negociadas com o OPL são: (i) multa de $20 \%$ por hora de atraso injustificado para entrega e/ou coleta de documentos e encomendas. Essa análise foi mensurada pelo indicador que menciona sobre-entrega expressa; (ii) multa de $10 \%$ quando for solicitada urgência e atenção à determinada carga e não for cumprido e (iii) multa de três vezes o valor do serviço relativo ao dano à remessa, mensurado pelo indicador irregularidade na entrega.

O indicador para a avaliação da urgência é o que mensura a rastreabilidade da carga. A multa será paga pelo OPL sobre o valor do serviço a ser pago no mês da infração. Procurou-se adotar um contrato detalhado similar ao documento descrito por Barros (2009).

A Tabela 3 aponta para o comparativo da variação percentual realizado entre os períodos de 2012 e 2013. Os dados da variação percentual permaneceram em sua maioria positivos de um período em relação ao outro. Somente em janeiro e fevereiro de 2013 os índices ficaram negativos, mas a justificativa é clara, uma que foi um período de integração e adaptação do OPL ao sistema logístico do banco. O OPL atingiu o nível de atendimento estabelecido no contrato a partir do mês de junho de 2013, com gradativa melhora a partir de outubro de 2013.

Tabela 3 - Comparativo e variação percentual dos Índices de eficiência entre 2012 e 2013

\begin{tabular}{|c|c|c|c|c|c|c|c|c|c|c|c|c|}
\hline Eficiência 2013 / 2012 & Jan & Fev & Mar & Abr & Mai & Jun & Jul & Ago & Set & Out & Nov & Dez \\
\hline Índice de Eficiência 2012 & $85 \%$ & $81 \%$ & $82 \%$ & $80 \%$ & $79 \%$ & $78 \%$ & $76 \%$ & $76 \%$ & $74 \%$ & $72 \%$ & $71 \%$ & $61 \%$ \\
\hline Índice de Eficiência 2013 & $71 \%$ & $75 \%$ & $82 \%$ & $85 \%$ & $88 \%$ & $90 \%$ & $90 \%$ & $90 \%$ & $90 \%$ & $91 \%$ & $92 \%$ & $93 \%$ \\
\hline Variação $\Delta \%$ & $-17 \%$ & $-7 \%$ & $0 \%$ & $6 \%$ & $12 \%$ & $15 \%$ & $19 \%$ & $18 \%$ & $22 \%$ & $26 \%$ & $30 \%$ & $52 \%$ \\
\hline
\end{tabular}

Fonte: Dados da pesquisa (2014)

Os dados mostraram a importância da transparência com o OPL na negociação e formalização contratual no que tange à implementação de desempenho logístico associado a multas em caso de ineficiência.

Na segunda tentativa em implantar o sistema logístico de transporte expresso por um OPL em 2013, a terceirização de serviços logísticos foi positiva para o banco, pois contribuiu para o foco nas competências-chave, reduziu custos, tempos de entregas e riscos, e consequentemente conseguiu aumentar a satisfação do cliente, semelhante aos achados nos estudos de Graf e Mudambi (2005), e Narasimhan, Narayana e Srinivasan (2010).

Este estudo mostrou um banco que terceirizou o sistema logístico de transporte expresso para um OPL. Em 2012, contratou um OPL e explicou apenas o processo logístico exigido que envolvesse somente a preocupação com a responsividade no que diz respeito à segurança e confiabilidade na entrega em just in time. Porém, os resultados não foram satisfatórios porque houve ineficiência no processo de contratação.

O banco não terceirizou a mensuração do desempenho e, por meio desta, foi possível verificar o insucesso. Porém, os gestores esperavam que o índice do indicador de eficiência do processo fosse aumentar, tendo como meta $95 \%$, mas os índices regrediram e a tendência era de diminuição. A decisão do banco foi de renegociação, exigindo melhorias, mas o OPL não tinha como melhorar a atuação devido à usabilidade máxima de sua capacidade. Sendo assim, a decisão foi de rescindir o contrato logístico no fim de dezembro de 2012.

Durante o processo de busca de um novo OPL, percebeu-se a necessidade de ampliar a relação com o OPL para que o resultado da terceirização obtivesse o sucesso esperado, isto é, não se atendo somente a medir o desempenho do contratado e exigindo resultados.

Por conseguinte, o banco percebeu a necessidade de interagir com o OPL na operação do dia 
a dia e construir esse resultado satisfatório em conjunto, para que gerasse a vantagem competitiva para o banco, ou seja, trabalhando com o OPL de maneira estratégica e não como um simples prestador de serviço.

\section{CONSIDERAÇÕES FINAIS}

O banco, depois do insucesso na terceirização do serviço logístico de carga expressa, teve de buscar no mercado outro OPL que pudesse atender às suas necessidades de responsividade e desempenho. Sendo assim, o negociador do banco decidiu ser mais transparente na elaboração e formalização contratual a respeito do indicador de eficiência no processo, associando multas em caso de ineficiência, utilizando os indicadores de desempenho para acompanhar o processo.

Os resultados mostraram melhorias no desempenho, uma vez que o banco era responsável de mensurar o desempenho e, pelo menos uma vez por mês, com base nesses índices de eficiência de processo, realizar reunião de avaliação entre o representante do banco e do OPL.

Essa reunião tinha como objetivo melhorias contínuas em conjunto com o contratado; dessa vez, considerando os funcionários da OPL como estratégicos na obtenção dos resultados do banco, e isso reduziu os conflitos entre os funcionários do banco e do OPL.

Espera-se que este estudo contribua com os gestores organizacionais no intuito de considerar a terceirização de operações logísticas como decisão estratégica em vez de operacional e o uso dos indicadores de desempenho para monitorar a eficiência do contratado.

Para estudos futuros, recomenda-se que estes indicadores de eficiência - capacidade efetiva em horas e capacidade realizada em horas - sejam aplicados em outros bancos quando terceirizarem operações logísticas de carga expressa e também em outros segmentos empresariais, para testar a eficácia dos mesmos.

\section{EXPRESS CARGO LOGISTIC SERVICE IN THE BANKING AREA: A SUCCESSFUL EXPERIENCE}

\section{ABSTRACT}

This case study is a comparison between two models of logistic services of a bank which, in 2012, decided to outsource to a logistic operator the activities of support and express logistic services for the delivery of cards, mail pouches, and registered documents. The method used is qualitative/ quantitative and was applied in semi-structured interviews and observation in the institution studied. Through the use of performance indicators, the results showed the situation prior to the outsourcing process in 2011. Then, the 2012 outsourcing process was evaluated and it indicated the results were not those expected by the bank. Finally, the period of 2013 with services provided by a new logistic operator was analysed. This time the process was successful. A relevant aspect of this case is to show the importance of implementing performance indicators to control the process for making decisions in what regards improvement and alignment of the business objectives besides also taking into account financial gains and strategic aspects of the outsourcing operation.

Keywords: Logistics. Logistic operator. Performance indicator. Express cargo.

\section{REFERÊNCIAS}

AKTAS, E. et al. The use of outsourcing logistics activities: The case of turkey. Transportation Research, Part C, Riverport Lane, v. 19, n. 5, p. 833-852, 2011.

BALLOU, R. H. Logística empresarial: transportes, administração de materiais e distribuição física. São Paulo: Atlas, 1993.

BARROS, M. Terceirização Logística no Brasil. [2009]. Disponível em: <www.ilos.com.br/site/index. php2option=com_content\&task=view\&id=738\&itemid=74>. Acesso em: 11 jun. 2014.

BENZI, L. D. Vaspex: Quebrando Paradigmas no Porta a Porta. Revista Tecnologística, São Paulo, v. 25, p. 36-38, 1997.

BOGDAN, R.; BIKLEN, S. Qualitative research for education: an introduction to theory and methods. Boston: Allyn and Bacon, 1992. 
BOWERSOX, D. J.; CLOSS, D. J; COOPER, M. B. Gestão logística de cadeia de suprimento. Porto Alegre: Bookman, 2006.

BREWER, A. M.; BUTTON, K. J.; HENSHER, D. A. Handbook of logistics and supply chain management. UK: Pergamon, 2001.

CAIXETA-FILHO, J. V.; MARTINS, R. S. (Org.) Gestão logística do transporte de cargas. São Paulo: Atlas, 2001.

CHERTO, M. Franchising: revolução no marketing. 3. ed. São Paulo: McGraw-Hill, 1988.

DENZIN, N. K.; LINCOLN, Y. S. Handbook of qualitative research. Thousand Oaks: Sage, 2005.

DI SERIO, L. C.; SAMPAIO, M. Projeto da cadeia de suprimento: uma visão dinâmica da decisão fazer versus comprar. RAE - Revista de Administração de Empresas, São Paulo, v. 41, n. 1, p. 54-66, 2001

DORNIER, P. P. et al. Logística e operações globais: texto e casos. São Paulo: Atlas, 2000.

EISENHARDT, K. M. Building theories from case study research. Academy of Management Review, New York, v. 14, n. 4, p. 522-550, 1989.

FINAMORE, F. G. et al. Fatores Relevantes da Logística Expressa (Porta a Porta) na ótica das MPE's. Jovens Pesquisadores, São Paulo, v. 4, n. 6, p. 1-15, jan./jun. 2007.

FLEURY, P. F.; RIBEIRO, A. F. M. A indústria de operadores logísticos no Brasil: uma análise dos principais operadores. São Paulo: ILOS, 2001 a.

FLEURY, P. F.; RIBEIRO, A. F. M. A Indústria de Prestadores de Serviços Logísticos no Brasil: Caracterizando os Principais Operadores. São Paulo: ILOS, 2001 b.

FLEURY, P. F.; WANKE, P.; FIGUEIREDO, K. F. Logística e gerenciamento da cadeia de suprimentos: planejamento do fluxo de produtos e dos recursos. São Paulo: Atlas, 2006.

FORSLUND, H. The impact of performance management on customers' expected logistics performance. International Journal of Operations and Production Management, Bradford, v. 27, n. 8, p. 901-918, 2007.

FUERTH, L. R.; DANTAS, L. S. O e-commerce e a integração logística no transporte de carga expressa. In: SIMPÓSIO DE EXCELÊNCIA EM GESTÃO E TECNOLOĢIA, 4., 2007, Resende. Anais... Rio de Janeiro: SEGeT, 2007.

GADDE, L. E.; HULTHEN, K. Improving Logistics Outsourcing through increasing buyer-provider interaction. Industrial Marketing Management, New York, v. 38, p. 633-640, 2009.

GIL, A. Como elaborar projetos de pesquisa. 4. ed. São Paulo: Atlas, 2002.

GRAF, M.; MUDAMBI, S. M. The outsourcing of IT-enabled business processes: a conceptual model of the location decision. Journal of International Management, Philadelphia, v. 11, n. 2, p. 253-268, 2005.

GRIFFIS, S. E. et al. Aligning logistics performance measures to the information needs of the firm. Journal of Business Logistics, Oak Brook, v. 28, n. 2, p. 35-56, 2007.

HARRIS, A.; GIUNIPERO, L. C.; HULT, T. M. Impact of organizational and contract flexibility on outsourcing contracts. Industrial Marketing Management, New York, v. 27, n. 5, p. 373-384, 1998.

HARRISON, A.; HOEK, R. V. Estratégia e gerenciamento da logística. São Paulo: Futura, 2003.

HAYATI, D.; KARAMI, E.; SLEE, B. Combining qualitative and quantitative methods in the measurement of rural poverty. Social Indicators Research, Atlanta, v. 75, n. 3, p. 361-394, 2006.

ILOS. Instituto de Pesquisa Supply Chain. Panorama de Terceirização Logística no Brasil (PTLB). [2009]. Disponível em: <www.ilos.com.br/site/index>. Acesso em: 11 jun. 2014.

LAUDON, K. C.; LAUDON, J. P. Sistemas de informação gerenciais: administrando a empresa digital. 5. ed. São Paulo: Pearson, 2004. 
LEITE FILHO, A. A. Uma contribuição ao Estudo de Indicadores da Qualidade do Serviço Padrão de Transporte de Carga Expressa no âmbito Nacional. 2006. 104 f. Dissertação (Mestrado em Engenharia de Transportes) - Universidade Federal do Rio de Janeiro - COPPEÁD, Rio de Janeiro, 2006.

MCCRACKEN, G. The Long Interview, Newbury Park: Sage, 1991.

MOREIRA, D. A. Administração da Produção e Operações. 2. ed. São Paulo: Cengage Learning, 2009.

MORGENSTEIN, M.; STRONGIN, H. Modern retailing. 3. ed. USA: Prentice Hall, 1992.

NARASIMHAN, R.; NARAYANAN, S.; SRINIVASAN, R. Explicating the mediating role of integrative supply management practices in strategic outsourcing: a case study analysis. International Journal of Production Research, London, v. 48, n. 2, p. 379-404, 2010.

NOVAES, A. G. Logística e gerenciamento da cadeia de distribuição: estratégia, operação e avaliação. Rio de Janeiro: Campus, 2007.

OLIVEIRA NETO, G. C. Integração complexa entre empresa contratante e operador logístico: critérios para a contratação. 2008. 119 f. Dissertação (Mestrado em Engenharia de Produção) Instituto de Ciências Exatas e Tecnológicas, Universidade Paulista - UNIP, São Paulo, 2008.

RODRIGUES, E. F. et al. Utilização de indicadores da qualidade para análise de eficiência dos processos em empresas de transporte rodoviário de cargas. INGEPRO - Inovação, Gestão e Produção, Santa Maria, v. 3, n. 9, p. 1-13, 2011.

SEIDMAN, I. E. Interviewing as Qualitative Research. A guide for researchers in education and the social sciences. New York: Teachers College/Columbia University Press, 1991.

SLACK, N.; CHAMBERS, S.; JOHNSTON, R. Administração da produção. 2. ed. São Paulo: Atlas, 2002.

TABOADA, C. Logística: o diferencial da empresa competitiva. Revista FAE Business, Curitiba, n. 2, p. 4-8, 2002.

TERAM, E. Organizational change within morally ambiguous contexts: A case study of conflicting post merger discourses. Journal of Applied Behavioral Science, Los Angeles. v. 46, n. 1, p. 38-54, 2010.

VENDRAMETTO, O.; OLIVEIRA NETO, G. C.; SANTOS, Gestão de materiais e operador logístico: um caso de relacionamento mal sucedido. In: Encontro Nacional de Engenharia de Produção, 28., 2008, Rio de Janeiro. Anais... Rio de Janeiro: ENEGEP, 2008. p. 1-14.

WOXENIUS, J. Directness as a key performance indicator for freight transport chain, Research in Transportation Economics, Hardbound, v. 36, n. 1, p. 63-72, 2012.

YIN, R. K. Estudo de caso: planejamento e métodos. 3. ed. São Paulo: Bookman, 2003. 